nhiên cần phải đánh giá kĩ các bệnh lý nền để kiểm soát trong ngưỡng ổn định trước khi tiến hành phẫu thuật. Việc lựa chọn vét hạch D2 hay dưới D2 cần cân nhắc dựa trên đặc điểm của từng người bệnh.

\section{TÀI LIÊU THAM KHẢO}

1. Đố Trường Sơn (2014). Điều trị phẫu thuâtt ung thư dạ dày ở người cao tuổi. $Y$ học Việt Nam. 418(2), 135-138.

2. Katai H., Ishikawa T., Akazawa $K_{\text {., }}$ et al (2018). Five-year survival analysis of surgically resected gastric cancer cases in Japan: a retrospective analysis of more than 100,000 patients from the nationwide registry of the Japanese Gastric Cancer Association (2001-2007). Gastric cancer. 21(1), 144-154.

3. Memon M., Subramanya M., Khan S., et al (2011). Meta-analysis of D1 versus D2 gastrectomy for gastric adenocarcinoma. Annals of surgery. 253(5), 900-911.
4. Mikami K., Hirano K., Futami K., et al (2018). Gastrectomy with limited surgery for elderly patients with gastric cancer. Asian journal of surgery. 41(1), 65-72.

5. Rausei S., Ruspi L., Rosa F., et al (2016). Extended lymphadenectomy in elderly and/or highly co-morbid gastric cancer patients: A retrospective multicenter study. European journal of surgical oncology. 42(12), 1881-1889.

6. Sung H., Ferlay J., Siegel R., et al (2021). Global cancer statistics 2020: GLOBOCAN estimates of incidence and mortality worldwide for 36 cancers in 185 countries. CA: a cancer journal for clinicians.

7. Yu J., Hu J., Huang C., et al (2013). The impact of age and comorbidity on postoperative complications in patients with advanced gastric cancer after laparoscopic D2 gastrectomy: Results from the Chinese laparoscropic gastrointestinal surgery study group. European Journal of Surgical Oncology. 39 (10), 1144-1149.

\title{
TÌM HIỂU BIẾN THIÊN NHİP TIM Ở BỆNH NHÂN ĐÁI THÁO ĐƯờNG TYP 2 CÓ ĐƯờNG HUYẾT KHÔNG ỔN ĐİNH
}

\section{TÓM TẮT}

Biến thiên nhịp timphản ánh tác động của thần kinh tự chủ lên tim và có giá trị tiên lượng khả năng xuất hiện rối loạn nhịp timnguy hiểm và tỷ lệ tử vong. Người bệnh Đái tháo đường có tỷ lệ cao biến chứng thần kinh tự chủ làm giảm chất lượng cuộc sống và tăng nguy cơ tử vong tim mạch. Mục tiêu của nghiên cứu này là: Khảo sát một số chỉ số biến thiên nhịp tim ở người bênh Đái tháo đường type 2 có đường huyết không ổn đinh bằng Holter điện tâm đồ 24 h và tìm hiểu mối tương quan giữa một số chỉ số biến thiên nhịp tim với nồng độ đường huyết ở đối tượng nghiên cứu. Đối tượng và phương pháp nghiên cứu: Mô tả cắt ngang 50 người bênh Đái tháo đường có đường huyết không ổn định được theo dõi Holter điện tâm đồ 24 giờ và đường máu mao mach 5 lần trong ngày. Kết quả nghiên cứu: Các chỉ sổ biến thiên nhịp tim như độ lệch chuẩn của các nhát bóp bình thường trên toàn bộ Hoter điện tim 24 giờ (SDNN), trung bình của độ lệch chuẩn tất cả các khoảng RR bình thường của tẩt cả các đoạn 5 phút trên toàn bộ Holter điện tim 24 giờ (ASDNN), độ lệch chuẩn của các khoảng RR bình thường trong mối 5 phút của toàn bộ Holter điện tim 24 giờ (SDANN),

\footnotetext{
${ }^{1}$ Bệnh viện Đa khoa tỉnh Hà Nam

2Viện Tim mạch Việt Nam - Bệnh viện Bạch Mai

Chịu trách nhiệm chính: Phạm Trần Linh

Email: ptlinhmd@gmail.com

Ngày nhận bài: 9.7.2021

Ngày phản biện khoa học: 3.9.2021

Ngày duyệt bài: 10.9.2021
}

\section{Trần Thị Tâm ${ }^{1}$, Phạm Trần Linh ${ }^{2}$}

trung bình của căn bậc hai tổng các bình phương đoạn RR (RMSSD) ở người bệnh Đái tháo đường typ 2 có đường huyêtt không ổn định đều thấp hơn so với người khỏe mạnh. Nhóm hạ đường huyết có các chỉ số biến thiên nhịp tim theo thời gian thấp hơn nhóm đường huyết cao. SDNN, ASDNN, SDANN tương quan thuận với $\mathrm{HbA} 1 \mathrm{c}$ ở nhóm đường huyết cao và tương quan nghịch với HbA1c ở nhóm ha đường huyết. Các chỉ số biến thiên nhip tim theo thời gian tương quan tương quan nghịch hoặc không có mối tương quan với nồng độ đường huyết các thời điểm kiểm tra. Thời khoảng QT hiệu chỉnh tối đa (QTc max) ở nhóm hạ đường huyết cao hơn nhóm đường huyết cao và có tương quan nghịch mức độ vừa với nồng độ đường huyết $6 \mathrm{~h}$ và $11 \mathrm{~h}$ trước ăn ở nhóm hạ đường huyết. Các rối loạn nhịp tim không tương quan với nồng độ đường huyểt. Kểt luận: Các chỉ số biến thiên nhịp tim theo thời gian ở bệnh nhân Đái tháo đường typ 2 thấp hơn so với người khỏe mạnh và có tương quan vừa với HbA1c, tương quan yếu với nồng độ đường huyêt.

Tì̛ khóa: Biến thiên nhịp tim, Đái tháo đường, Đường huyết không ổn định.

\section{SUMMARY \\ HEART RATE VARIABILITY IN DIABETES MELLITUS TYP 2 PATIENTS WITH UNCONTROL BLOOD GLUCOSE LEVELS}

Heart rate variability (HRV) reflects cardiac autonomic nervous function and predicts risk of serious arrhythmia and mortality. Diabetes mellitus patients have high rate cardiac autonomic nervous dysfunction and arterial diseases, so they are reduced quality of life and significantly increased cardiovascular 
mortality. The aim of this study was to examine Heart rate variability in diabetes mellitus participants with uncontrol blood glucose level and the relationship between heart rate variability and blood glucose level from 24-h Holter electrocardiogram recordings. Method: We performed a cross - sectional study included 50 diabetes mellitus participants with unstable blood glucose level from 24-h Holterelectrocardiogram recordings and was followed by a finger prick blood glucose assessment glucose 5 times (6h-11h-13h-17h-21h). Results: SDNN(Standard deviation of all normal sinus R-R intervals), ASDNN (The mean of the standard deviation of all normal sinus R-R intervals for all 5-minute segments of the entire recording), SDANN (Standard deviation of the averaged normal sinus R-R intervals for all 5 minute segments of the entire recording), RMSSD (The root mean square of the difference between the coupling intervals of adjacent R-R intervals) are lower in diabetes mellitus participants than normal. HRV in hypoglycemia group is lower no significant than hyperglycemia group's. Correlation analysis identified that there was no significant relationship between any HRV time domain parameter and blood glucose level in the diabetes mellitus participants. SDNN, ASDNN, SDANN in hyperglycemia group was significantly correlations with $\mathrm{HbA} 1 \mathrm{c}$ but no significantly negatively correlated in hypoglycemia group. QTc max was longer in hypoglycemia group and was negatively correlated with blood glucose levels at 6 a.m, 11 a.m (fasting plasma glucose). There was no correlations between arrhythmia and blood glucose levels. Conclusions: HRV time domain parameters in Diabetes mellitus typ 2 patients are lower than normal and moderate correlations with $\mathrm{HbA1c}$, weak correlations with blood glucose levels.

Keywords: Heart rate variability, diabetes mellitus, uncontrol blood glucose levels.

\section{I. ĐẶT VẤN ĐỀ}

Đái tháo đường là bệnh được đặc trưng bởi tình trạng tăng đường máu mạn tính phối hợp với rối loạn chuyển hóa carbohydrate, lipid và protein do thiếu hụt của tình trạng tiết insulin, tác dụng của insulin hoăc cả hai. Ngoài các biến cố về bệnh lý mạch máu do xơ vữa, tỷ lệ mắc và tử vong do biến chứng thần kinh tự chủ (TKTC) ở người bệnh Đái tháo đường cao và làm tăng nguy cơ tử vong tim mạch với đột quy. Biến thiên nhịp tim là sự biến đổi thời khoảng R-R trên điện tim của các chu chuyển tim kế tiếp nhau trong một khoảng thời gian nhất định, phản ánh sự tác động của hệ thần kinh tự chủ trên tim. Biển thiên nhịp tim có giá trị tiên lượng khả năng xuất hiện rối loạn nhịp nguy hiểm và tỷ lệ tử vong. Vì vậy chúng tôi tiến hành nghiên cứu này nhằm 2 mục tiêu:

1. Khảo sát một số chỉ số biến thiên nhịp tim ở bênh nhân Đái tháo đường type 2 có đường huyêt không ổn định bằng Holter điện tâm đồ 24h.
2. Tìm hiểu mối tương quan giữa một số chi số biến thiên nhịp tim với nồng độ đường huyêt ở các bệnh nhân nghiên cứu.

II. ĐỐI TƯỢNG VÀ PHƯƠNG PHÁP NGHIÊN CỨU

- Đối tượng nghiên cứu: 50 người bệnh Đái tháo đường có đường huyết không ổn định điều trị nội trú tại Bệnh viện Bạch Mai và Bệnh viện Đại học Y Hà Nội trong thời gian từ tháng 8 năm 2020 đến tháng 8 năm 2021.

- Phương pháp nghiên cứu: Mô tả cắt ngang 50 người bệnh Đái tháo đường có đường huyết không ổn định được chia làm 2 nhóm: nhóm đường huyết cao là những đối tượng có đường huyết chưa đạt mục tiêu điêu trị theo ADA 2020 và nhóm hạ đường huyết là những đối tượng có HbA1c đạt mục tiêu điêu trị nhưng có cơn hạ đường huyết ${ }^{1}$. Đối tượng nghiên cứu được theo dõi holter điện tâm đồ 24 giờ và thử đường máu mao mạch 5 lần trong ngày đeo holter và được khảo sát các thông số sau:

+ Các chỉ số biến thiên nhịp tim (BTNT) theo thời gian:

- SDNN: Độ lệch chuẩn của các nhát bóp bình thường trên toàn bộ Hoter điện tim 24 giờ, đơn vi tính theo ms

- ASDNN: Trung bình của độ lệch chuẩn tất cả các khoảng $R R$ bình thường của tất cả các đoạn 5 phút trên toàn bộ Holter điện tim 24 giờ, đơn vị ms

- SDANN: Độ lệch chuẩn của các khoảng RR bình thường trong mỗi 5 phút của toàn bộ Holter điện tim 24 giờ, đơn vị ms

- RMSSD: Trung bình của căn bậc hai tổng các bình phương đoạn RR tính theo ms

+ Tần số tim, ngoại tâm thu thất, ngoại tâm thu nhĩ, QTc

+ Đường máu mao mạch các thời điểm: 6h11h-13h-17h-21h, HbA1c

-Xử lý số liệu: Số liệu thống kê được phân tích và xử lý bằng phần mềm SPSS 18.0

\section{KẾT QUẢ NGHIÊN CỨU}

\section{1. Đối tượng nghiên cứu}

Bảng 1: Đặc điếm đối tượng nghiên cứu

\begin{tabular}{|c|c|}
\hline Đắc điếm & Kết quả \\
\hline Giới nam(n, \%) & $25(50 \%)$ \\
\hline Tuối trung bình & $62,06 \pm 12,47$ \\
\hline HbA1c(\%) & $9,72 \pm 2,76$ \\
\hline Rối loạn thần kinh tự chủ $(n, \%)$ & $21(42 \%)$ \\
\hline $\begin{array}{l}\text { Thời gian mắc Đái tháo đường } \\
\text { (năm) }\end{array}$ & $4,7 \pm 4,68$ \\
\hline
\end{tabular}

3.2 Đặc điểm biến thiên và rối loạn nhịp đối tượng nghiên cứu 
Bảng 2: Biến thiên nhịp tỉm và rôi loạn nhịp, QTc của nhóm nghiên cứu

\begin{tabular}{|c|c|c|c|c|c|c|}
\hline BTNT & $\begin{array}{c}\text { Đường máu } \\
\text { cao (n=32)(1) }\end{array}$ & $\begin{array}{c}\text { Hạ đường máu } \\
(\mathbf{n = 1 8} \mathbf{( 2 )}\end{array}$ & $\begin{array}{c}\text { chung } \\
\mathbf{( 3 )}\end{array}$ & $\begin{array}{c}\text { Người bình } \\
\text { thương } \mathbf{2}(\mathbf{4})\end{array}$ & $\begin{array}{c}\mathbf{P} \\
\mathbf{3 \& 4}\end{array}$ & $\begin{array}{c}\mathbf{P} \\
\mathbf{1} \mathbf{2}\end{array}$ \\
\hline SDNN(ms) & $91,04 \pm 28,22$ & $77 \pm 32,03$ & $85,98 \pm 30,1$ & $117,18 \pm 3,7$ & 0,000 & 0,114 \\
\hline SDANN(ms) & $75,56 \pm 24,95$ & $62,8 \pm 32,03$ & $70,96 \pm 26,6$ & $99,34 \pm 3,49$ & 0,000 & 0,105 \\
\hline ASDNN(ms) & $47,52 \pm 22,59$ & $36,03 \pm 22,2$ & $43,39 \pm 22,9$ & $57,69 \pm 1,99$ & 0,000 & 0,08 \\
\hline RMSSD(ms) & $26,47 \pm 10,24$ & $27,16 \pm 13,5$ & $26,71 \pm 11,3$ & $36,25 \pm 1,56$ & 0,000 & 0,84 \\
\hline QTcmin(ms) & $376,81 \pm 30,8$ & $359,67 \pm 22,9$ & $370,6 \pm 29,2$ & NA & & 0,045 \\
\hline QTc mean(ms) & $423,46 \pm 14,1$ & $416,11 \pm 18,1$ & $420,8 \pm 15,9$ & NA & & 0,118 \\
\hline QTcmax(ms) & $439,78 \pm 6,21$ & $445,44 \pm 11,1$ & $441,8 \pm 8,63$ & NA & & 0,024 \\
\hline NTTN & $141,1 \pm 416,4$ & $309,1 \pm 1042,2$ & $201 \pm 702,3$ & NA & & 0,179 \\
\hline NTTT & $307,2 \pm 865,6$ & $184,39 \pm 327,7$ & $263 \pm 717,5$ & NA & & 0,984 \\
\hline
\end{tabular}

3.3 Mối tương quan một số chỉ số biến thiên nhịp tim và rối loạn nhịp với nồng độ đường huyết

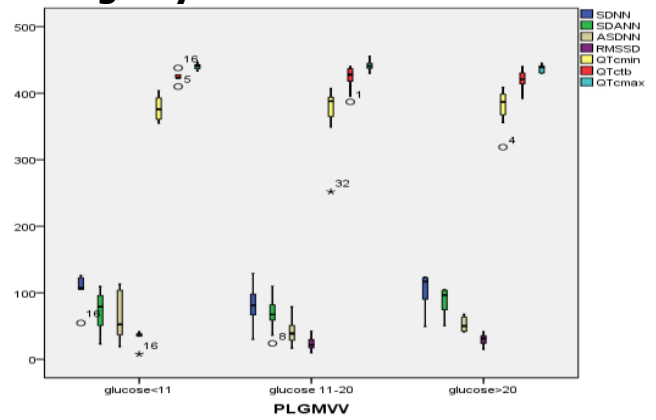

Biểu đồ 1: Biến thiên nhịp tím và QTc của nhóm đường huyêt cao

Nhận xét: Ở nhóm đường huyết cao các chỉ số SDNN, ASDNN, RMSSD giảm khi đường máu tăng. QTc giữa các nhóm khác biệt không ý nghĩa thống kê.

Bảng 3: Môii tương quan các chỉ số biến thiên nhịp tỉm và rôi loạn nhịp với nồng độ đường huyêt ở nhóm đường huyết cao

\begin{tabular}{|c|c|c|c|c|c|c|c|}
\hline \multicolumn{2}{|c|}{ glucose } & 6h & 11h trước ăn & 11h sau ăn & 17h & 21h & HbA1c \\
\hline \multirow{2}{*}{ SDNN } & $r$ & 0,143 & $-0,187$ & 0,004 & 0,21 & 0,061 & 0,313 \\
\hline & $\mathrm{p}$ & 0,435 & 0,305 & 0,984 & 0,248 & 0,742 & 0,081 \\
\hline \multirow{2}{*}{ SDANN } & $r$ & $-0,092$ & $-0,172$ & $-0,171$ & $-0,027$ & 0,071 & 0,293 \\
\hline & $\mathrm{p}$ & 0,615 & 0,347 & 0,412 & 0,884 & 0,701 & 0,104 \\
\hline \multirow[t]{2}{*}{ ASDNN } & $r$ & $-0,187$ & 0,043 & 0,043 & 0,223 & $-0,065$ & 0,094 \\
\hline & $\mathrm{p}$ & 0,305 & 0,816 & 0,816 & 0,219 & 0,725 & 0,609 \\
\hline \multirow{2}{*}{ RMSSD } & $r$ & $-0,08$ & $-0,098$ & 0,01 & 0,132 & 0,042 & 0,3 \\
\hline & $\mathrm{p}$ & 0,664 & 0,593 & 0,958 & 0,47 & 0,821 & 0,096 \\
\hline \multirow{2}{*}{ QTC min } & $r$ & 0,25 & 0,149 & 0,045 & $-0,216$ & 0,135 & 0,04 \\
\hline & $p$ & 0,168 & 0,415 & 0,807 & 0,236 & 0,848 & 0,827 \\
\hline \multirow{2}{*}{$\begin{array}{c}\text { QTc } \\
\text { mean }\end{array}$} & $r$ & 0,06 & 0,049 & $-0,184$ & $-0,222$ & 0,195 & $-0,009$ \\
\hline & $p$ & 0,973 & 0,788 & 0,312 & 0,222 & 0,604 & 0,96 \\
\hline \multirow{2}{*}{ QTc max } & $r$ & 0,167 & 0,219 & $-0,178$ & $-0,258$ & 0,289 & $-0,181$ \\
\hline & $\mathrm{p}$ & 0,36 & 0,228 & 0,329 & 0,154 & 0,109 & 0,321 \\
\hline \multirow{2}{*}{ NTTN } & $r$ & $-0,133$ & $-0,214$ & 0,033 & 0,32 & $-0,207$ & $-0,036$ \\
\hline & $p$ & 0,468 & 0,24 & 0,859 & 0,074 & 0,254 & 0,846 \\
\hline \multirow{2}{*}{ NTTT } & $r$ & $-0,038$ & 0,094 & $-0,167$ & 0,162 & 0,222 & 0,05 \\
\hline & $p$ & 0,837 & 0,608 & 0,37 & 0,377 & 0,222 & 0,785 \\
\hline
\end{tabular}

Bảng 4: Mối tương quan các chỉ số biến thiên nhịp tîm và rối loạn nhịp với nồng độ đường huyết ở nhóm hạ đường huyêt

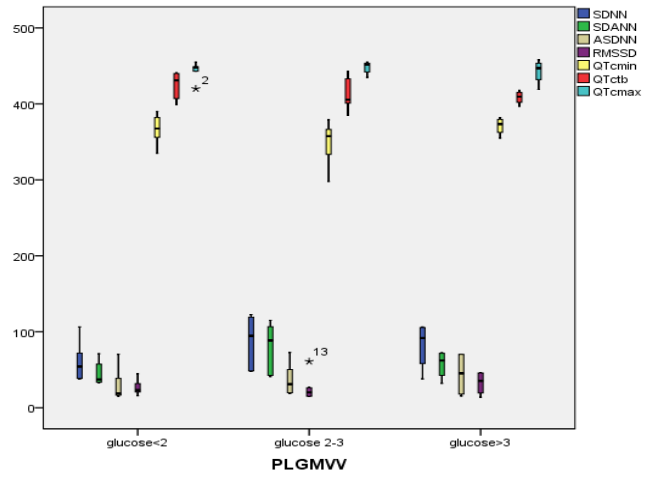

Biêu đồ 2: Biến thiên nhịp tîm và QTc của nhóm hạ đường huyêt

Nhận xét: các chỉ số BTNT thấp ở nhóm đường máu < $2 \mathrm{mmol} / \mathrm{l}$. 
VIETNAM MEDICAL JOURNAL N¹ - OCTOBER - 2021

\begin{tabular}{|c|c|c|c|c|c|c|c|}
\hline \multicolumn{2}{|c|}{ glucose } & $\mathbf{6 h}$ & $\mathbf{1 1 h}$ trước ăn & $\mathbf{1 1 h}$ sau ăn & $\mathbf{1 7 h}$ & $\mathbf{2 1 h}$ & HbA1c \\
\hline \multirow{2}{*}{ SDNN } & $\mathrm{r}$ & 0,289 & $-0,05$ & $-0,093$ & 0,253 & $-0,043$ & $-0,111$ \\
\cline { 2 - 8 } & $\mathrm{p}$ & 0,246 & 0843 & 0,715 & 0,311 & 0,866 & 0,662 \\
\hline \multirow{2}{*}{ SDANN } & $\mathrm{r}$ & 0,25 & $-0,014$ & $-0,126$ & 0,146 & $\mathbf{- 0 , 3 5}$ & $-0,037$ \\
\cline { 2 - 8 } & $\mathrm{p}$ & 0,317 & 0,957 & 0,619 & 0,562 & 0,89 & 0,883 \\
\hline \multirow{2}{*}{ ASDNN } & $\mathrm{r}$ & 0,086 & $-0,1$ & $-0,215$ & 0,281 & 0,033 & $-0,167$ \\
\cline { 2 - 8 } & $\mathrm{p}$ & 0,733 & 0,692 & 0,391 & 0,259 & 0,989 & 0,507 \\
\hline \multirow{2}{*}{ RMSSD } & $\mathrm{r}$ & $-0,03$ & $-0,121$ & 0,2 & 0,133 & $-0,036$ & $-0,049$ \\
\cline { 2 - 8 } & $\mathrm{p}$ & 0,906 & 0,632 & 0,426 & 0,599 & 0,887 & 0,848 \\
\hline \multirow{2}{*}{ QTC min } & $\mathrm{r}$ & $\mathbf{- 0 , 2 2 6}$ & $\mathbf{- 0 , 4 0 8}$ & 0,056 & $-0,21$ & $-0,289$ & 0,013 \\
\cline { 2 - 8 } & $\mathrm{p}$ & $\mathbf{0 , 0 1 7}$ & $\mathbf{0 , 0 5 5}$ & 0,826 & 0,403 & 0,454 & 0,959 \\
\hline \multirow{2}{*}{ QTcmean } & $\mathrm{r}$ & $\mathbf{- 0 , 4 6 6}$ & $-0,238$ & 0,157 & $-0,31$ & $\mathbf{- 0 , 3 1 9}$ & 0,271 \\
\cline { 2 - 8 } & $\mathrm{p}$ & 0,05 & 0,342 & 0,533 & 0,211 & 0,198 & 0,278 \\
\hline \multirow{2}{*}{ QTC max } & $\mathrm{r}$ & $\mathbf{- 0 , 5 5 3}$ & $\mathbf{- 0 , 6 1 8}$ & 0,247 & $-0,2$ & $-0,212$ & $\mathbf{0 , 4 7 3}$ \\
\cline { 2 - 8 } & $\mathrm{p}$ & $\mathbf{0 , 2 2}$ & $\mathbf{0 , 0 0 6}$ & 0,324 & 0,2 & 0,492 & 0,047 \\
\hline
\end{tabular}

\section{BÀN LUÂN}

4.1 Biến thiên nhịp tim và rối loạn nhịp ở người bênh Đái tháo đường typ 2 có đường huyểt không ổn định. Kết quả nghiên cứu cho thấy các chỉ số BTNT giảm rõ rệt so với người khỏe mạnh, sự khác biệt có ý nghĩ̉a thống kê với $p<0,001$. Kết quả nghiên cứu của chúng tôi tương tự của $\mathrm{H}$ Kukat, Vladan Vukomanovica 3,4 . Khi so sánh các chỉ số biến thiên nhịp tim theo thời gian ở 2 nhóm nghiên cứu cho kết quả các chỉ số biến thiên nhịp tim ở nhóm hạ đường huyết thấp hơn nhóm đường huyết cao, khác biệt không ý nghĩa thống kê với $p>0,05$. Các chỉ số SDNN, RMSSD thấp nhất ở nhóm có đường huyết thấp nhất. Ảnh hưởng của sự thay đổi đường huyết lên biến thiên nhịp tim là do các tác động chuyển hóa chung có hại lên cả hoạt động phó giao cảm và phó giao cảm ${ }^{5}$. Các bộ phận giao cảm và phó giao cảm của TKTC đều bị ảnh hưởng bởi glucose máu tăng, quá trình viêm, stress oxy hóa có thể gây ra tổn thương DNAtăng tạo ra các sản phẩm protein biến dạng làm thay đổi cấu trúc và chức năng cơ quan. Tăng đường huyết cũng làm suy yếu quá trình tái tạo tế bào thần kinh và cho rằng sự gia tăng của các superoxide trong huyết tương có thể dự báo sự suy giảm chức năng TKTC tim mạch ${ }^{6}$. Nhóm đường huyết cao có số lượng ngoại tâm thu thất cao hơn nhóm ha đường huyết, còn nhóm hạ đường huyết có số lượng ngoại tâm thu nhĩ trung cao hơn nhóm đường huyết cao, nhưng sự khác biệt không có ý nghĩa thống kê. Hoạt động quá mức của thần kinh giao cảm có liên quan đến tình trạng kháng insulin và là nguyên nhân tăng tỷ lệ rối loạn nhịp ở người bệnhĐTÐ typ 2 kiểm soát kém. Thời gian ban ngày, đáp ứng của giao cảm thượng thận ưu thế đối với hạ đường huyết có liên quan đển kéo dài đoạn QT và nhịp tim. Trong quá trình ha đường huyết về đêm, các giai đoạn khác nhau của sự thay đổi nhịp tim chỉ ra rằng phản ứng giao cảm ban đầu đối với hạ đường huyết sau đó là phản ứng phó giao cảm với biểu hiện là nhịp chậm ${ }^{7}$.

4.2 Mối tương quan một số chỉ số biến thiên nhịp tim và nồng độ đường huyết. Khi khảo sát mối tương quan các chỉ số biến thiên nhịp tim theo thời gian với nồng độ $\mathrm{HbA1c}$ có tương quan đồng biến mức độ vừa với $r=0,23$ đến 0,31 . Tuy nhiên khi khảo sát theo từng nhóm thì cho kết quả các chỉ số biến thiên nhịp tim theo thời gian ở nhóm hạ đường huyết tương quan nghịch rất yếu và gần như không tương quan với $\mathrm{HbA1c}$ với $r$ từ $-0,167$ đến $-0,037$, $\mathrm{p}>0,05$. Còn ở nhóm đường huyết cao các chỉ số biên thiên nhịp tim theo thời gian tương quan đồng biến, mức đô vừa với $\mathrm{HbA1c}$ với $\mathrm{r}=0,293$ đến 0,313 , tuy nhiên không có ý nghĩa thống kê với $p>0,05$. Các chỉ số biến thiên nhịp tim theo thời gian ở cả 2 nhóm đường huyêt cao và ha đường huyết có tương quan nghịch mức độ yếu với đường huyết các thời điểm, không có ý nghĩa thống kê với p>0,05.Khi tìm mối tương quan các giá trị QTc với nồng độ đường huyết ở các thời điểm trong ngày 6 giờ, 11 giờ trước và sau ăn, 17 giờ, 21 giờ chúng tôi thấy tương quan rõ nhất ở nhóm hạ đường huyết các giá trị QTc max, min, trung bình có tương quan nghịch với nồng độ đường huyết đặc biệt ở thời điểm 6 giờ sáng và 11 giờ trước ăn với $r=-0,618$ đến $-0,446$. Đây cũng là 2 thời điểm mà người bệnh của nhóm nghiên cứu hay được phát hiện hạ đường huyết nhất trong thời gian đeo máy. Còn ở nhóm đường huyết cao sự tương quan yếu gần như không tương quan giữa QTc và đường máu với $r=-0,258$ đến $0,289, p>0,05$.

\section{KẾT LUÂ̂N}


Các chỉ số BTNT theo thời gian ở người bệnh Đái tháo đường typ 2 có đường huyết không ổn định giảm hơn so với người bình thường. SDNN, ASDNN, SDANN tương quan thuận với HbA1c ở nhóm đường huyết cao và tương quan nghịch mức độ vừa với HbA1c ở nhóm hạ đường huyết và tương quan yếu với nồng độ đường huyết.

\section{TÀI LIỆ THAM KHẢO}

1. Guideline ADA 2020. Glycemic Targets: Standards of Medical Care in Diabetes-2020 | Diabetes Care.

2. Huỳnh Văn Minh. Holter Điện Tâm Đồ 24h Trong Bệnh Lý Tim Mạch.

3. Kudat, H.; và cs. Heart Rate Variability in Diabetes Patients. J. Int. Med. Res.2006, 34 (3), 291-296.
4. Vukomanovic, V. và cs. Association between Functional Capacity and Heart Rate Variability in Patients with Uncomplicated Type 2 Diabetes. Blood Press.2019, 28 (3), 184-190.

5. Benichou, T. và cs. Heart Rate Variability in Type 2 Diabetes Mellitus: A Systematic Review and Meta-Analysis. PLOS ONE 2018, 13 (4), e0195166.

6. Victoria L Fisher và cs. Cardiac autonomic neuropathy in patients with diabetes mellitus: current perspectives. Dovepress J. Diabetes, Metabolic Syndrome and Obesity: Targets and Therapy 2017:10 419-434.

7. Chow, E; và cs. Risk of Cardiac Arrhythmias During Hypoglycemia in Patients With Type 2 Diabetes and Cardiovascular Risk. Diabetes 2014, $63(5), 1738-1747$.

\section{ĐÁNH GIÁ KẾT QUẢ ĐIỀU TRI PHẪU THUÂT XUẤT HUYẾT TIÊU HÓA DO UNG THƯ HANG MÔN VỊ DẠ DÀY XÂM LẤN ĐẦ TỤY, DI, DII TÁ TRÀNG}

\section{TÓM TẮT}

Xuất huyết tiêu hóa (XHTH) do ung thư hang môn vị da dày là một biến chứng của ung thư da dày. Cho tới nay việc điều trị phẫu thuật (PT) còn gặp nhiều khó khăn do bệnh nhân (BN) thường đến muộn, khối ung thư đã xấm lấn những thành phần xung quanh, DI, DII tá tràng, đâuu tụy, cuống gan... do đó PT trớ thành thách thức lớn giứa PT triệt căn, PT làm sach hay PT tạm thời. Mặt khác, cấu trúc giải phẫu và đặc điểm sinh lý vùng cuống gan, tá tràng, đâu tụy phức tạp nên phâu thuật có tỷ lệ thất bại, tai biến và biến chứng khá cao, khó thực hiện. Bởi vậy chúng tôi tiến hành nghiễn cứu này với mục tiêu: Đánh giá kết quả điều trị phẫu thuật XHTH do ung thư hang môn vị xâm lấn DI, DII tá tràng, đầu tụy. Phương pháp nghiên cứu (NC): Phương pháp mô tả hồi cứu. Đối tượng NC: Bệnh nhân được chẩn đoán XHTH do ung thư hang môn vị dạ dày, được điều trị PT tại khoa ngoại bụng 2, bệnh viện $K$, có tổn thương trong mổ là ung thư hang môn vị xâm lấn đầu tụy và/hoặc DI, DII tá tràng. Đia điểm: Bênh viện $K$ K Trung ương. Thời gian: 1/2019-12/2020. Kết quả nghiên cứu: Có 8 bênh nhân, $100 \%$ là nam, tuổi trung bình: 59,9 tuổi; $6 \dot{2}, 5 \%$ lia phân đen, $37,5 \%$ nôn máu và ía phân đen, $75,0 \%$ khám sớ thây khối u, thiếu máu nhe: $5 / 8(62,5 \%)$, thiếu máu vừa: 3/8.(37,5\%). Nội soi dạ dày(NSDD): Forrest Ib: $1 / 8(12,5 \%)$, Forrest IIc: $7 / 8(87,5 \%), 75 \%$ ung thư hang môn vị, hẹp môn vị (HMV), 25\% ung thư hang môn vị xâm lấn DI, DII. Tổn thương trong mổ: $87,5 \%$ ung thư đã xâm lấn DI,

*Bệnh viện $K$

Chịu trách nhiệm chính: Thái Nguyên Hưng

Email: Thainguyenhung70@gmail.com

Ngày nhận bài: 7.7.2021

Ngày phản biên khoa họ: 3.9.2021

Ngày duyệt bài: 10.9.2021

\section{Thái Nguyên Hưng*}

DII, 12,5\% ung thư xâm lấn đầu tụy, 3/8(37,5\%) ung thư thủng (xâm lấn DI, DII, thủng vào đâu tụy). Xử trí PT: $100 \%$ các trường hợp được cắt $4 / 5 \mathrm{DD}$, đóng mỏm tá tràng mũi rời kiểu con sện (khó khăn), 01 BN đóng mỏm tá tràng kết hợp dẫn lưu ( $\mathrm{DL}$ ) mỏm tá tràng. Không có $B N$ nào tử vong. Biến chứng sau mổ: $1 \mathrm{BN}$ viêm tụy cấp hoại tử, rò miêng nối điều trị nộ khoa. Kết quả GPB: Giai đoạn IB:1(12,5\%), giai đoạn IIIA: $3(37,5 \%)$, giai đoạn IİIB: $3(37,5 \%)$, giai đoạn IIIC:1 (12,5\%). Kết luân: XHTH do ung thư hang môn vị dạ dày xâm lấn DI, DII tá tràng, đầu tuy là ung thư dạ dày đến muộn, có thể đã thủng vào DI DII tá tràng, đâu tự. Đa số tổn thương DI, DII tá tràng và đầu tuy chỉ được phát hiện trong mổ. Xử trí PT khó khăn,có thể đóng mỏm tá tràng mũi rời (kiểu con sên) hoặc dẫn lưu mỏm tá tràng.

\section{SUMMARY \\ TO EVALUATE THE SURGICAL RESULT OF BLEEDING DISTAL GASTRICCANCER INVALIDING DI,DII DUODENUM AND HEAD OF PANCREAS}

Bleeding distal gastric cancer invading DI,DII duodenum and head of pancreas is a complication of distal gastric cancer. The lesions could be combination of pyloric stenosis, perforgation to DI,DII of duodenum. The surgical management needed good technical skills of closing duodenum stump as well as making ist drainage in case of closing stump dundenum dificulty. Study aims: To Evaluate the result of surgical management of bleeding distal gastric cancer that invade DI, DII duodenum and/or head of pancreas. Patient and methode: Retrospective study.All the patients who had bleeding distal gastric cancer invading the head of pancreas and/or DI, DII of Duodenum. Period: 1/201912/2020. Results: 8 patients, $100 \%$ males, mean age 